\title{
DIAGNOSTIC OF TEMPERATURE DISTRIBUTION IN THE CHAMBER OF GA PLASMA REACTOR
}

\author{
Jarosław Diatczyk ${ }^{1}$, Joanna Pawłat ${ }^{1}$, Henryka Danuta Stryczewska' \\ 1 Institute of Electrical Engineering and Electrotechnologies, Faculty of Electrical Engineering and Computer \\ Science, Lublin University of Technology, Nadbystrzycka 38d, Lublin, Poland, e-mail: j.diatczyk@pollub.pl
}

Received: 2016.08 .16 Accepted: 2016.09.26 Published: 2016.11.01

\begin{abstract}
Different diagnostic methods can be used to determine electrons and gas temperatures in the gliding arc plasma reactor. The electrons' temperature has been determined by optical spectroscopy and gas temperature - by thermovision camera. The results of the thermovision diagnostics of the plasma generated by gliding arc for different process gases and their flow rates are presented and discussed in the paper.
\end{abstract}

Keywords: plasma diagnostic, non-thermal plasma, plasma reactors

\section{INTRODUCTION}

Nowadays, atmospheric pressure low temperature plasmas are applied in many industrial processes. They are: treatment of flue gases emitted by industrial processes of combustion, painting and varnishing, wastes utilization, deodorization, disinfection and sterilization [Stryczewska et al. 2013], material processing and new material manufacturing for application in microelectronics and nanotechnologies. Non-thermal and non-equilibrium plasma-based methods allow treatment of organic materials, like rubber, fabrics, biomaterials [Koval'ová 2013] and they are ecologically justified alternative for chemical ones [Addou et al 2005, Brisset \& Pawłat 2016].

In Poland, the plasma processes, although investigated in research laboratories, are applied in industry at much smaller scale than in industrialized countries of Europe and the rest of the world [Sawicki \& Krouchinin 2000]. Polish power industry is based on fossil fuels combustion that emits pollution in form of sulfur and nitrogen oxides, soot and ashes, which have to be disposed of. Plasma technologies can be a reasonable alternative for chemical, gypsum-based wet methods, environmentally noxious, still applied in power industrial practice.
Investigations in the field of industrial application of plasma chemical methods, conducted in many research centers and universities in Poland and abroad, are now concentrated on obtaining controllable plasma parameters and chemical reactions in a large volume of treated gases [Pawłat et al. 2011]. Repeatability of the plasma-chemical process depends on stability of plasma parameters, which influence the proper chemical reaction path. The main parameters are the chemical composition of the plasma gas, its pressure, flow rate, geometry of plasma reactor and electrical parameters of power system, i.e. value and form of supply voltage, power, and frequency [Mazurek 2011].

Arc discharge can be a source of non-thermal and non-equilibrium plasma at certain conditions of power supply system, geometry of reactor electrodes and gas flow rate [Heeren et al. 2005]. The gliding arc discharge plasma is an example of this kind of low temperature plasma that can be generated in multi-electrode reactors at atmospheric pressure.

Gliding arc reactor considerably differs from other non-thermal plasma sources [Czernichowski 1994, Lesueur et al. 1990]. The resistance of inter-electrode gap depends on the kind of gas, its flow rate, degree of ionization and it also changes its value in wide range during the single opera- 
tion cycle [Diatczyk et al. 2011]. Moreover, the discharge is displacing through electrodes periodically starting from the thermal short arc in the least electrode distance and increases its volume and length with the fast gas flow and electrodes' spacing growth. Plasma generated in the gliding arc reactor is in non-equilibrium state: the temperature of "hot electrons" $\left(T_{\mathrm{e}}\right)$ is much higher than gas temperature $\left(T_{\mathrm{g}}\right)$ [Diatczyk 2012].

This kind of source of high energy electrons without heating the plasma gas in the whole volume of plasma reactor chamber is essential for typical plasma chemistry applications.

\section{EXPERIMENTAL METHODS}

Different diagnostic methods can be used to determine electrons and gas temperature. The electrons' temperature has been determined by optical spectroscopy and gas temperature - by thermovision camera. Optical diagnostic of the gliding arc discharge plasma can be a reliable source of information on concentrations and temperatures of plasma components in atmospheric gases [Diatczyk et al. 2006]. Non-equilibrium condition of plasma generated by gliding arc discharge, including changes of ionization type from thermal to non-thermal, together with low resolution of CCD spectrometers requires specific approach to its spectral diagnostic $[10,11]$.

The purpose of spectral diagnostic of plasma generated in gliding arc discharge reactor is to determine the plasma particles energy distribution.
Based on the estimated temperatures $T_{\mathrm{e}}, T_{\text {rot }}$ and $T_{\text {vib }}$ we can conclude equilibrium or non-equilibrium character of generated plasma.

The main problem in the optical plasma diagnostic is difficult manual calculation $[10,11]$ of particle temperatures from the plasma emission spectrum. In order to confirm to non-equilibrium of generated plasma we only need to know electron temperature $\left(T_{\mathrm{e}}\right)$ and gas temperature $\left(T_{\text {rot }}\right)$. The electron temperature can be easily estimated based on relative intensities of argon emission lines and gas temperature can be measured with a thermovision camera.

\section{RESULTS AND DISCUSSION}

\section{Experimental setup}

We use the VIGO System V-20 ER005-10 thermovision camera (Fig. 1) with spatial resolution $-3.5 \times 10^{-3}$ rad and spectral range $3-5 \times 10^{-6}$ $\mathrm{m}$. It measures averaged in time gas temperature (10 s for matrix; $0.1 \mathrm{~s}$ for single line). In experiment the focal length is: $1.20 \mathrm{~m}$ for horizontal position, $0.90 \mathrm{~m}$ for vertical position and $1.10 \mathrm{~m}$ for look down view.

For optical diagnostic we use a USB spectrometer based on CCD line, Solar TII SL40-23648 USB. The spectrometer can provide spectra in range $190 \times 10^{-9}-1100 \times 10^{-9} \mathrm{~m}$ with optical resolution of about $1 \times 10^{-9} \mathrm{~m}$. Plasma was generated in the chamber of gliding arc plasma reactor (Fig. 2) in argon, nitrogen and air, respectively.

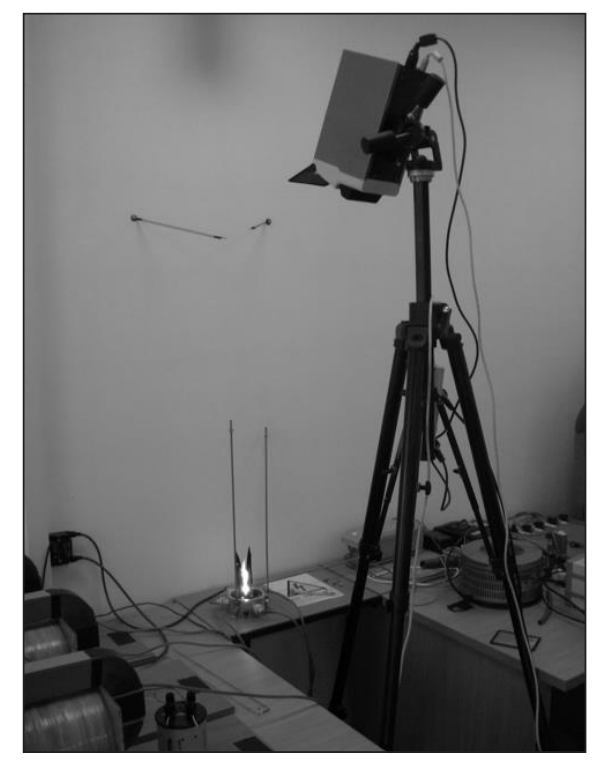

Figure 1. Thermovision camera

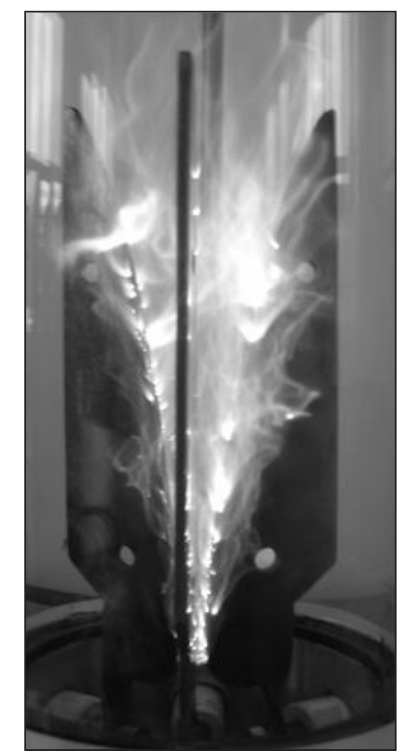

Figure 2. GA plasma reactor. 
We use different gas flow rates - ranging from $0.3 \mathrm{~m}^{3} / \mathrm{h}$ to $3.5 \mathrm{~m}^{3} / \mathrm{h}$. The gas flow lesser than $0.5 \mathrm{~m}^{3} / \mathrm{h}$ was used only for argon, in which discharge can be sustained at much lower voltage than in nitrogen and air. Gas temperature has been measured along two axes: horizontal and vertical (Fig. 3). Diagnostic conditions and reactor geometry are given in table 1 .

\section{Thermovision diagnostic results}

Based on results of the thermovision diagnostic, temperature distribution in the discharge chamber of the plasma reactor for different argon flow rates has been studied (Fig. 4).

The temperature inside the chamber of plasma reactor decreases with the growth of the argon flow rate (Fig. 4). For argon flow rates lesser than $1.0 \mathrm{~m}^{3} / \mathrm{h}$ the temperature changes are insignificant. Argon flow rate change in the range from $0.3 \mathrm{~m}^{3} / \mathrm{h}$ to $1.0 \mathrm{~m}^{3} / \mathrm{h}$ causes the temperature changes lesser than $10 \%$. Increase the argon flow rate above $1.0 \mathrm{~m}^{3} / \mathrm{h}$ results in significant fall of the temperature inside the reactor chamber.

Moreover, changes of the temperature distribution in the chamber of the plasma reactor for different gases and constant flow rate have been examined (Fig. 5).

Chemical composition of the processing gas together with gas flow rate growth causes the changes of temperature distribution in the gliding arc discharge chamber. In the case of nitrogen and air, the temperature inside the chamber of the plasma reactor is about 30\% higher in comparison to argon as a processing gas.

Table 1. Conditions of the temperature measurements

\begin{tabular}{|l|c|}
\hline $\begin{array}{l}\text { Discharge chamber } \\
\text { geometry }\end{array}$ & \\
\hline chamber diameter & $0.080 \mathrm{~m}$ \\
\hline electrode length & $0.141 \mathrm{~m}$ \\
\hline $\begin{array}{l}\text { electrode distance in the } \\
\text { ignition area }\end{array}$ & $(1-6)^{\prime} 10^{-3} \mathrm{~m}$ \\
\hline $\begin{array}{l}\text { electrode distance in the } \\
\text { extinction area }\end{array}$ & $0.030-0.035 \mathrm{~m}$ \\
\hline Gas parameters & argon, air, nitrogen \\
\hline process gases & $0.3-3.5 \mathrm{~m}^{3} / \mathrm{h}$ \\
\hline gas flow rates & \\
\hline $\begin{array}{l}\text { Power supply system } \\
\text { parameters }\end{array}$ & $400-1500 \mathrm{~V}$ \\
\hline inter-electrode voltage & $1.0-3.5 \mathrm{~A}$ \\
\hline electrode current & \\
\hline
\end{tabular}

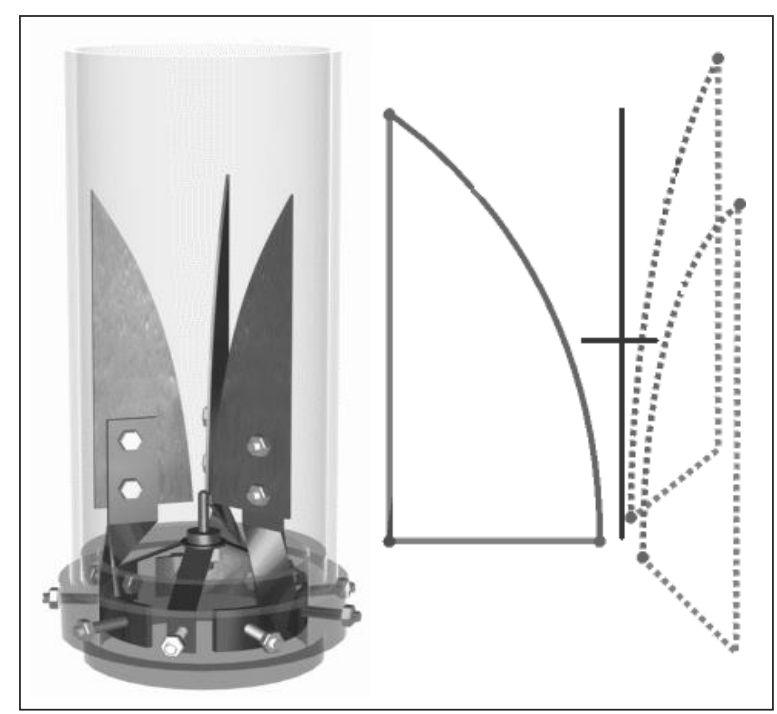

Figure 3. Vertical and horizontal lines for thermovision measurements.

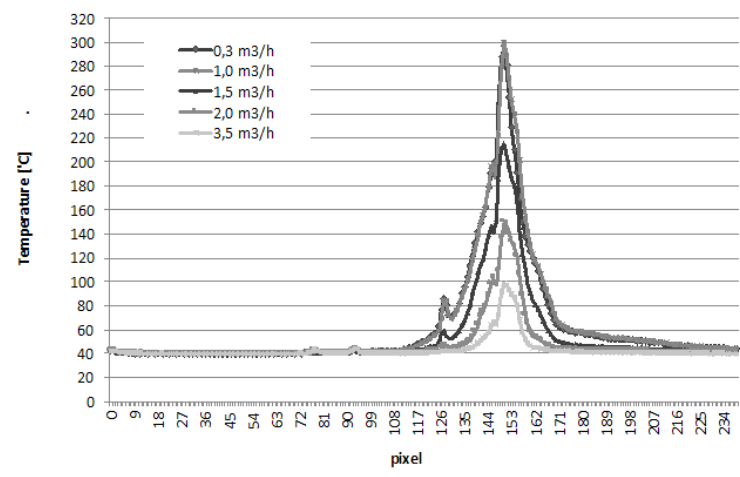

Figure 4. The temperature distribution in the chamber of gliding arc plasma reactor for different argon flow rates.

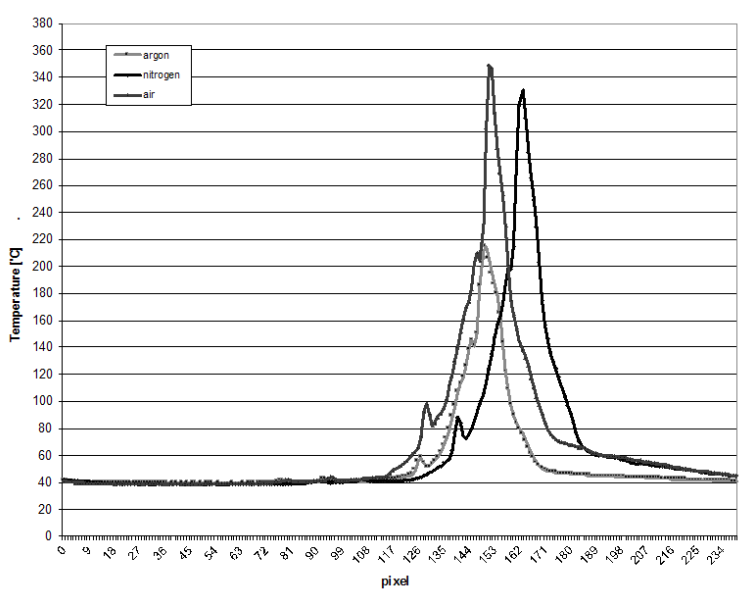

Figure 5. The temperature distribution in the chamber of gliding arc plasma reactor for different gases and constant flow rate $\left(1.5 \mathrm{~m}^{3} / \mathrm{h}\right)$. 


\section{Spectroscopic diagnostic results}

The electrons' temperature $\left(T_{\mathrm{e}}\right)$, which corresponds to the electron population distribution, has been determined by spectroscopic method on the basis of Boltzmann plot by using the relative intensities of copper $(\mathrm{Cu})$ emission lines: $465.1 \cdot 10^{-9}$ $\mathrm{m}, 510.5 \cdot 10^{-9} \mathrm{~m}, 515.3 \cdot 10^{-9} \mathrm{~m}, 521.8 \cdot 10^{-9} \mathrm{~m}$, $578.2 \cdot 10^{-9} \mathrm{~m}$, respectively. Selection of these lines is conditioned as follows [10]:

- there is no overlapping of these lines with other spectral lines and bands,

- the energy differences between the upper excited levels of spectral transitions are high enough to reduce inaccuracy in temperature estimations.

Determination of the vibration temperature $T_{\text {vib }}$ (the temperature of vibration levels population distribution) was based on measuring relative intensities of nitrogen $\left(\mathrm{N}_{2}\right)$ spectral emission bands. This method assumed that vibration temperatures of the ground state and electronic excited states are very closed. The vibration temperature $T_{\text {vib }}$ can be also determined from the Boltzmann plot.

Generally, in non-equilibrium air plasmas, distribution of electronic population can be different from the Boltzmann plot [Raniszewski 2013]. Therefore, at first we must check the Boltzmann energy distribution law.

Spectroscopic measurements were performed for argon, air and nitrogen at flow rates from $0.5 \mathrm{~m}^{3} / \mathrm{h}$ to $3.5 \mathrm{~m}^{3} / \mathrm{h}$. The spectra presented in the Figure 6 how that technological gases used in experiments contain impurities (Fig. 6). The plasma gas contains also contains coming from electrodes due to the spark erosion [Присяжневич et al. 2005]. Reactor electrodes applied in experiments made of acid-resistance steel consist quite large content of chrome and nickel, and also some manganese, titanium, molybdenum and copper.

\section{CONCLUSIONS}

Temperature distribution in the discharge chamber of plasma reactor with gliding arc is a very important factor from the point of view of plasma chemistry, and determines the technological application of this kind of plasma.

Gas temperature can be determined with the aid of thermovision technique, while electrons energy, usually several times greater than that of gas, from optical spectroscopy. Combination of these methods can be a suitable tool for estimation plasma non-equilibrium.

The optical on-line analysis of the plasma spectrum during the discharge together with current and voltage measurements can be used to control the dynamic characteristics of the gliding arc plasma reactor almost in real time. The spectroscopic characterization of the gliding arc discharge plasma can also be useful in explaining the mechanism of its transition from equilibrium to non-equilibrium state and to giving directions how to design power system in order to ensure the time of the non-equilibrium and non-thermal plasma state much longer than the equilibrium and thermal one.

The temperature in the chamber of plasma reactor declines along with the growth of the gas flow rate [14].

Argon used as the processing gas causes significantly lower temperature inside the chamber of the plasma reactor.

Electron temperature (about $8000 \mathrm{~K}$ ) in the gliding arc discharge plasma obtained by opti-
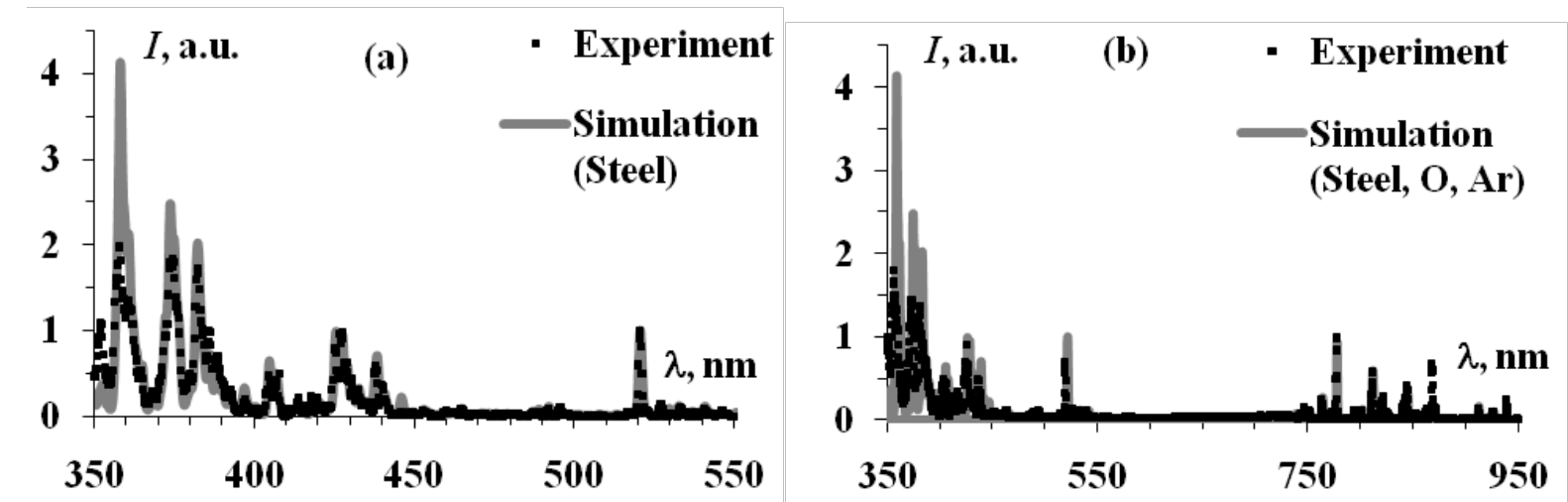

Figure 6. Emission spectra of GA plasma in (a) air and (b) argon. Simulation at characteristic temperatures: $T_{\mathrm{e}}(\mathrm{Fe}, \mathrm{Cr}, \mathrm{Ni})=8000 \mathrm{~K}, T_{\mathrm{e}}(\mathrm{Ar})=7000 \mathrm{~K}, T_{\mathrm{e}}(\mathrm{O})=6000 \mathrm{~K}$ 
cal spectroscopy diagnostic referenced to the gas temperature (about $600 \mathrm{~K}$ ) from thermovision camera indicates that the generated plasma is non-thermal and non-equilibrium.

\section{Acknowledgements}

Part of the research was done under support from COST Actions TD 1208 and MP1101, KORANET and funds from Lublin University of Technology.

\section{REFERENCES}

1. Addou, R.M. Ghezzar, F. Abdelmalek, J.L. Brisset, 2005, Proceedings of ISPC-17, CD.

2. Brisset J.-L., Pawłat J. 2016, Chemical effects of air plasma species on aqueous solutes in direct and de-layed exposure modes: discharge, post-discharge and plasma activated water, Plasma Chemistry and Plasma Processing, 36(2), 355-381.

3. Czernichowski A. 1994, Pure Appl. Chem. 66 (6), 1301.

4. Diatczyk J. 2012, Modeling discharge length for GA plasma reactor, Przegląd Elektrotechniczny, 6, 89-91.

5. Diatczyk J., Komarzyniec G., Stryczewska H. D., 2011, Power Consumption of Gliding Arc Discharge Plas-ma Reactor, International Journal of Plasma Environment Science \& Technology (IJPEST), 5(1), 12-16.

6. Diatczyk J., Stryczewska H.D., Komarzyniec G., 2006, Modeling of the Temperature Distrbution in
Arc Dis-charge Plasma Reactor, Journal of Advanced Oxidation Technologies, 9(2), 174-177.

7. Heeren T. Ueno, D. Wang, T. Namahira, S. Katsuki, H. Akiyama, 2005, IEEE Transaction on Plasma Sci-ence, 33(4), 1205.

8. Koval’ová Z., Tarabová K., Hensel K., Machala Z., 2013, Decontamination of Streptococci biofilms and $\mathrm{Ba}$-cillus cereus spores on plastic surfaces with DC and pulsed corona discharges, Eur. Phys. J. Appl. Phys., 61(2), 24306.

9. Lesueur H., Czernichowski A. and Chapelle J., 1990, French Patent 2639172.

10. Mazurek P.A., 2011, Zaburzenia promieniowane reaktora plazmowego typu GlidArc, Przegląd Elektrotech-niczny, 12b, 121-124.

11. Pawłat J., Diatczyk J., Stryczewska H. 2011, Low-temperature plasma for exhaust gas purification from paint shop - a case study, Przegląd Elektrotechniczny, 1(87), 245-248.

12. Raniszewski G. 2013, Temperature measurements in arc-discharge synthesis of nanomaterials dedicated for medical applications EPJAP 6124311.

13. Sawicki A.M. Krouchinin 2000. IEEE Transactions on Plasma Science, 28(1), 242.

14. Stryczewska H., Pawłat J., Ebihara K., 2013, Non-thermal plasma aided soil decontamination, JAOTs 1(16), 23-30

15. Wang, A. Kuthi, M.A. Gundersen, 2005. IEEE Transaction on Plasma Science, 33(4), 1177.

16. Присяжневич І.В., Черняк В.Я., Коротков П.А., Наумов В.В., Бабіч І.Л., Слюсаренко Ю. І., Юхыменко В.В., Зражевский В.А., 2005, Вісник Київ. Ун-ту. Серія:фіз.-мат. Науки, 1, 289-298. 